This article has been published in Journal of Materials Processing Technology. The final publication is available at Elsevier via https://doi.org/10.1016/j.jmatprotec.2018.10.029

\title{
Comparison of the semi-solid constitutive behaviour of A356 and B206 aluminum foundry alloys
}

\author{
F. Sheykh-jaberi ${ }^{1}$, S.L. Cockcroft ${ }^{1}$, D.M. Maijer ${ }^{1}$, A.B. Phillion ${ }^{2}$ \\ ${ }^{1}$ Dept. of Materials Engineering, The University of British Columbia, Vancouver, Canada \\ ${ }^{2}$ Dept. of Materials Science and Engineering, McMaster University, Hamilton, Canada
}

\begin{abstract}
The semi-solid constitutive behaviour of two commercially important aluminum foundry alloys, AA B206 and AA A356, has been quantified using a Gleeble thermo-mechanical physical simulation system. For these tests, a series of samples were extracted from a directionallysolidified wedge casting. The samples were further classified by their microstructure, average grain size of 128,220 , or $325 \mu \mathrm{m}$ for B206, and average secondary dendrite arm spacing (SDAS) of 43, 90, or $124 \mu \mathrm{m}$ for $\mathrm{A} 356$. The results indicate that at high solid fraction, $0.95<f_{\mathrm{s}}<1$, B206 had a higher yield stress than A356. However, at lower solid fraction, $f_{\mathrm{s}}<0.95, \mathrm{~A} 356$ had the higher yield stress. In both alloys, an increase in the microstructure (grain size or SDAS), resulted in a decrease in the semi-solid ductility. The effect of microstructure on yield stress was minimal. The minimum solid fraction when the yield stress reached a very low value, known as the rigidity point, was shown to be 0.93 and 0.80 for B206 and A356, respectively. This significant difference in rigidity demonstrates the importance of the eutectic on reducing hot tearing susceptibility.

Keywords: Metal casting, aluminum alloys, semi-solid constitutive behaviour, Hot tearing, microstructure.
\end{abstract}

\section{Introduction}

Shape casting of aluminum alloys provides a cost-effective way for manufacturing components of complex geometry for a variety of applications within the automotive and aerospace industries. Recently, there has been significant interest in replacing traditional aluminum foundry alloys such as AA 356 with high strength compositions like AA 206 owing to the additional weight savings that can be realized with enhanced properties. As noted by (Eskin, 2008), however, the dominant issue arising when casting AA 206 is its high susceptibility to hot tearing, limiting the process yields that can be achieved. The desire to use AA 206 in geometrically 
complex castings, e.g. wheels, cylinder heads, suspension components, and engine blocks, represents both a significant engineering opportunity and challenge from the perspective of casting these materials.

The alloy AA B206 is an advanced version of AA 206, a heat treatable Al-Cu alloy, that was developed by (Major and Sigworth, 2006) with strict limits of Fe and Ti content. The alloy AA A356 alloy is a mature variant of AA 356, a heat treatable Al-Si-Mg alloy with strict limits on the Fe and $\mathrm{Zn}$ content. As noted by (Heydari et al., 2014), trace elements play a significant role in hot tearing susceptibility in all engineering metals. This is clearly seen in the specification for B206 and A356. The hot tearing susceptibility of B206 and A356 alloys can be inferred, to a first approximation, through analysis of their solidification path and phase formation. (Haghdadi et al., 2015) quantified the evolution in solid fraction with temperature for B206 as having a relatively long freezing range $\left(505-643^{\circ} \mathrm{C}\right)$ and a mainly primary phase structure with only $\sim 5 \%$ eutectic. (Thompson et al., 2004) quantified the evolution in solid fraction with temperature for A356 as having a relatively short freezing range $\left(535-616^{\circ} \mathrm{C}\right)$ and containing approximately $50 \%$ primary phase and $50 \%$ eutectic.

Reviews by (Sigworth, 1996), (Eskin et al., 2004) and (Li et al., 2012) summarize the work completed thus far on hot tearing in aluminum alloys including experimental investigations and some of the assessment criteria. From their reviews, it is clear that the semi-solid constitutive behaviour is highly dependent on temperature, strain rate, alloy microstructure and the test methodology. The alloys A356 and B206 have received some attention by previous researchers in this regard. (Nguyen T G et al., 1994) and (Benke et al., 2009) carried out semi-solid tensile tests on A356 at strain rates of 0.008 and $0.005 \mathrm{~s}^{-1}$, respectively, characterizing the failure stress and strain at high solid fraction. The results obtained from these two studies showed nearly a threefold difference in semi-solid yield stress for a given solid fraction with Nguyen's being higher for all tests. It is unclear why this difference arose. (Mohseni et al., 2016) and (Bolouri et al., 2016) performed similar experiments on B206. However, the former were compression tests and not tensile tests that are more consistent with the conditions leading to hot tearing, while the latter mainly focused on the microstructure, fracture surface, and crack propagation mechanisms and not the semi-solid constitutive behaviour. (Lemieux et al., 2012) studied the effect of high silicon content and varying copper levels on hot tearing sensitivity in B206. They showed that through semi-solid forming the $\mathrm{Si}$ content could be increased to above $0.05 \%$ without compromise on 
mechanical properties. Although the increase in $\mathrm{Si}$ significantly decreased hot tearing susceptibility, the semi-solid forming process is only suitable for a subset of shape castings. (D'Elia et al., 2014) investigated the mechanisms of hot tearing in B206 using neutron diffraction and showed that additions of $\mathrm{Ti}$ to the alloy were effective at eliminating hot tearing by transforming the grain structure from coarse dendrites to finer and more globular grains. They further showed that hot tears occurred at solid fraction ranging from 0.81 to 0.87 . It is unclear why their values of solid fraction were so much lower than the ones typically accepted by the community for hot tear initiation. Recently, (Hamadellah et al., 2017) quantified semisolid deformation in $\mathrm{AlCu} 5 \mathrm{MgTi}$, an alloy similar to B206, using instrumented constrained six rods casting method. They showed that the contraction load increased significantly just prior to hot tearing. However, the long-term viability of this apparatus for reducing hot tearing susceptibility was not clearly articulated.

Recently, Gleeble thermomechanical simulators have been used to establish the semi-solid tensile behaviour of different alloys. The significant advantage of the Gleeble apparatus is the use of Joule heating to rapidly heat the sample, this increases the accuracy and reliability of measured results and assures that the microstructure tested does not deviate significantly from the as-cast structure during the testing. Both (Van Haaften et al., 2002b) and (Colley et al., 2004) performed tensile tests on an AA5182 alloy at temperatures up to $580^{\circ} \mathrm{C}\left(f_{1}=0.07\right)$ and found that strain rate can significantly affect the semi-solid tensile properties. However, the stresses measured by Colley were two to three times larger than those measured by Van Haaften. This difference can be related to differences in chemical composition and test sample geometry, as well as the experimental methodology. (A. B. Phillion et al., 2008), using an Al-Mg alloy, demonstrated that pre-existing as-cast porosity significantly reduces semi-solid ductility. (Fabrègue et al., 2006a), using an Al-Mg-Si alloy, showed that the mechanisms of semi-solid deformation were different upon cooling from the liquid as compared to re-heating from the solid. In the first case, the remaining liquid was located at the grain boundaries, while in the second it was also found in the grain interior. In a second study, (Fabrègue et al., 2006b) investigated the behaviour of semi-solid Al-2wt.\%Si and AA6056 aluminum alloys and found that hot tearing does not occur at solid fractions greater than 0.95 . The main challenges in using re-melting tests to measure semi-solid constitutive behaviour relate to maintaining the as-cast microstructure during reheating, and to having accurate knowledge of the liquid fraction during 
testing. Furthermore, testing is only possible at high solid fraction. In alloys with high eutectic content, there can be large changes in the amount of liquid present with only small variations in temperature, which may lead to significant variability in the test results.

As shown by this brief literature review, thermo-mechanical testing of semi-solid materials has been successful in determining the alloy rigidity point, and in quantifying hot tearing susceptibility. Nevertheless, these studies lack important details regarding sample microstructure (both grain size and grain morphology), alloy chemistry, and the role of phase content. In particular, the role of the eutectic seems to be unclear. In this study, the semi-solid constitutive behaviour of the B206 and A356 aluminum foundry alloys is characterized, with a focus on the effect of microstructure and solid fraction on ductility and yield strength. The differences between these two alloys provides a good opportunity to gain additional insights into the factors that influence hot tearing.

\section{Experimental}

The experimental method consisted of first casting B206 and A356 alloys into a purpose-built wedge-shaped mould. The compositions for the two alloys are given in Table 1. The castings were then machined to produce the test samples used to conduct semi-solid tensile tests. The wedgeshaped mould was designed to achieve directional solidification with a range of solidification rates/microstructures varying from relatively fast/fine near the wedge base to slow/course near the top. Normal to the thermal gradient, the microstructure was uniform in terms of grain size and secondary dendrite arm spacing. This allowed for examination of the effects of microstructure on semi-solid constitutive properties.

Figure 1 shows the evolution of solid fraction versus temperature for both alloys. As can be seen, the solidification range of B206 is approximately $140^{\circ} \mathrm{C}$ compared with $80^{\circ} \mathrm{C}$ for A356. Note also the virtual absence of a thermal arrest in B206, consistent with the small eutectic volume fraction in this alloy, compared with the large thermal arrest associated with the eutectic reaction in A356 $\left(\sim 577^{\circ} \mathrm{C}\right)$, which accounts for approximately $50 \%$ by volume in the final microstructure.

Table 1 - Composition of the Alloys Tested

\begin{tabular}{|l|l|l|l|l|l|l|l|}
\hline Alloy & $\mathrm{Cu}$ & $\mathrm{Mg}$ & $\mathrm{Mn}$ & $\mathrm{Fe}$ & $\mathrm{Si}$ & $\mathrm{Zn}$ & $\mathrm{Ti}$ \\
\hline B206 & $4.2-5.0$ & $0.15-0.35$ & $0.2-0.5$ & $<0.1$ & $<0.05$ & $<0.1$ & 0.1 \\
\hline A356 & $<0.1$ & $0.25-0.45$ & $0.05-0.1$ & $<0.2$ & $6.5-7.5$ & $<0.1$ & 0.2 \\
\hline
\end{tabular}




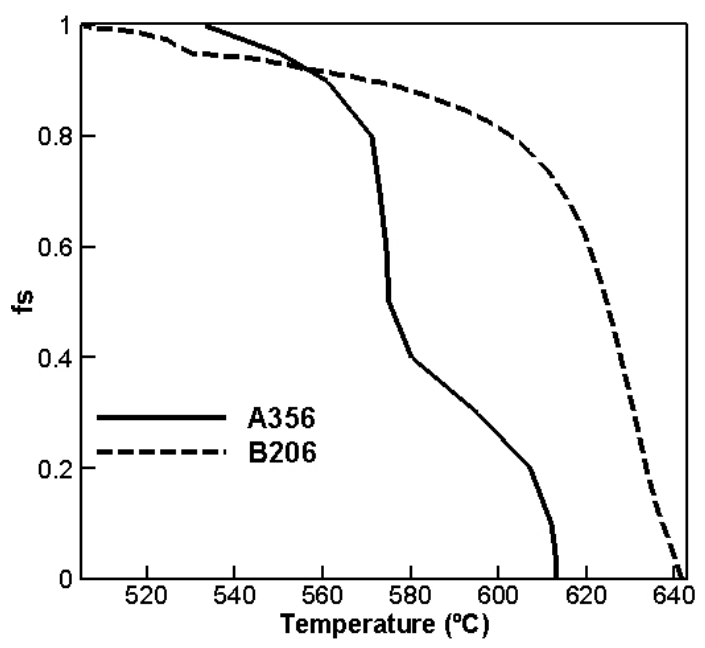

Fig. 1 Evolution in solid fraction for B206 (Haghdadi et al., 2015), A356 (Thompson et al., 2004).

\subsection{Casting}

The B206 and A356 feedstocks were melted in a graphite crucible within a resistance furnace to $800^{\circ} \mathrm{C}$ and $700^{\circ} \mathrm{C}$, respectively, prior to casting. The hydrogen level of each melt was reduced by bubbling Ar gas through it for $5 \mathrm{~min}$. Note that the final $\mathrm{H} 2$ level was not measured. The fixtures for the mould feeding system are shown in Figure 2 (a) including the pour basin, sprue, runner, and wedge cavity end-plates. A water-cooled copper chill, placed at the bottom of the wedge, acted as the primary heat sink for removing heat from the liquid metal. In order to achieve directional solidification, the inner surfaces of the wedge end-plates and the left and right sides of the wedge were made from HT-1 millboard ${ }^{1}$ insulation. The same material was used for the interior surfaces of the gate. To create the tapered geometry, the thickness of the wedge was increased from $12 \mathrm{~mm}$ at the bottom to $50 \mathrm{~mm}$ at the top. In total, four B206 and four A356 wedges were cast.

\subsection{Sample machining}

Twelve cylindrical tensile specimens were machined using wire-EDM from each of the wedge castings normal to the casting direction. Each sample was taken a minimum of $5 \mathrm{~mm}$ below the tapered wedge surface. The intent was to have each group of samples (bottom, middle and top) contain approximately the same microstructure in terms of grain size and secondary dendrite arm spacing. Figure 3 (a) provides a schematic showing the location of each sample, while Figure 3 (b) shows the test specimen geometry, with a central gauge region of $10 \mathrm{~mm}$ (1) and $6 \mathrm{~mm}$ (dia).

\footnotetext{
${ }^{1}$ The material is a ceramic free composition of mineral wool and inert fillers, and was supplied by Pyrotek (Van Haaften et al., 2002a)
} 
(a)

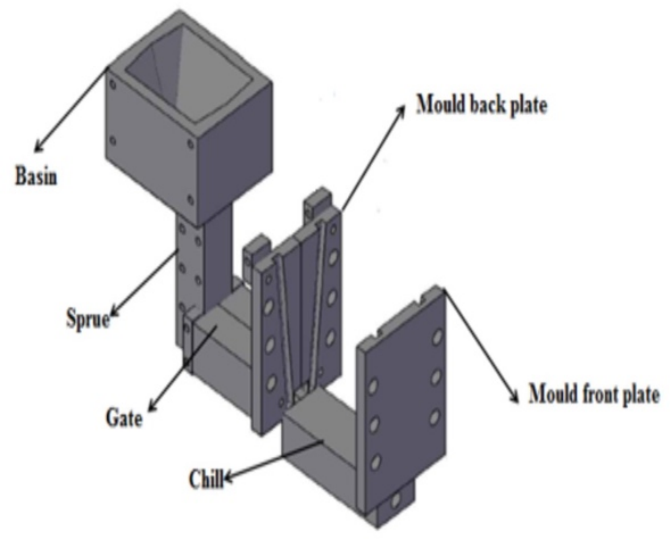

(b)

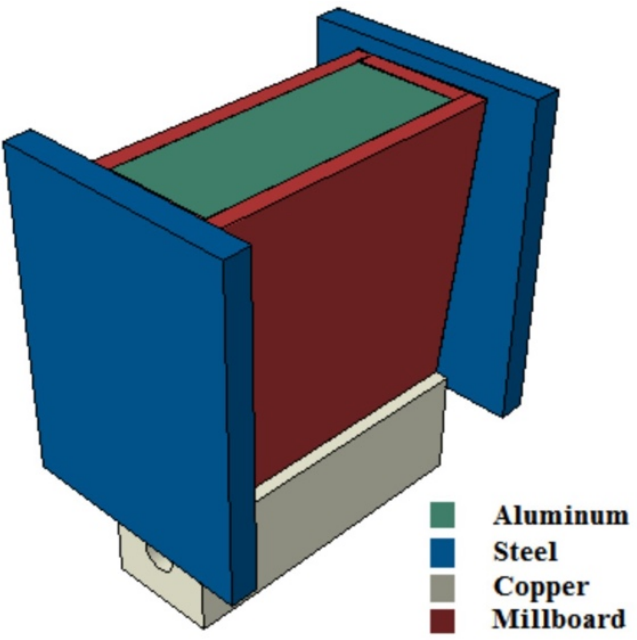

Fig. 2 (a) Schematic illustration of the gating system and mold cavity; (b) details of wedge casting assembly and materials. (See online version for colour images)

\subsection{Thermo-mechanical testing}

The semi-solid deformation tests were carried out using a Gleeble-3500 thermo-mechanical simulator. The deformation tests were conducted as follows: first, the Gleeble chamber was evacuated to 0.4 torr and then filled with Ar gas. Second, each specimen was rapidly heated up to $400^{\circ} \mathrm{C}$ at a heating rate of $5^{\circ} \mathrm{C} / \mathrm{s}$. Third, the heating rate was reduced to $1^{\circ} \mathrm{C} / \mathrm{s}$ until the test temperature was reached. This was followed by an isothermal hold of $20 \mathrm{~s}$. Lastly, the samples were deformed at a strain rate of $0.003 \mathrm{~s}^{-1}$. Figure 4 (a) shows the time-temperature relationship during one test, where the sample was heated to $500{ }^{\circ} \mathrm{C}$. In total, 30 tests were conducted between $500^{\circ} \mathrm{C}$ and $570^{\circ} \mathrm{C}$.

Within the Gleeble-3500 apparatus, heating is achieved via the Joule effect. This enables very fast heat rates minimizing microstructural changes via coarsening. However, control of this process requires a thermocouple directly in contact with the sample. Thermocouples are normally spot welded, however, tests conducted in the semi-solid regime can often result in detachment of the thermocouple. This is especially problematic in alloys containing a significant volume fraction of eutectic, such as A356, as a result of the formation of a significant volume fraction of liquid over a relatively small temperature range. In this study, a looped thermocouple method was developed to provide better control of the temperature at the center of the semi-solid sample. This 
consisted of looping a thermocouple around the diameter, at the center of the gauge length, to eliminate thermocouple detachment. This enabled semi-solid tensile testing using the Gleeble apparatus at temperatures (liquid volume fractions) higher than previously conducted.

Note that it was assumed that the gauge region of the tensile test sample was isothermal during mechanical testing, and further, was iso fraction solid. Although this is a significant assumption, the large change in radius between the gauge region $(3 \mathrm{~mm})$ and grips $(5 \mathrm{~mm})$ helps to promote temperature uniformity across the length. In the radial direction, the relatively low melting point of Al minimizes radiative losses. The joule heating also promotes temperature radial uniformity.

\subsection{Microstructural Characterization and Fractography}

Samples were obtained at each location in the wedge to be examined optically in order to characterize the as-cast microstructure. The procedure involved polishing the samples down to 1 $\mu \mathrm{m}$ using a standard method and then etching them. The A356 samples were etched with Krolls Reagent (92 $\mathrm{ml}$ distilled water, $6 \mathrm{ml}$ nitric acid, and $2 \mathrm{ml}$ hydrofluoric acid solution). The B206 samples were etched with Weck's Reagent (100 ml distilled water, $4 \mathrm{~g} \mathrm{KMnO}_{4}$, and $1 \mathrm{~g} \mathrm{NaOH}$ ).

(a)

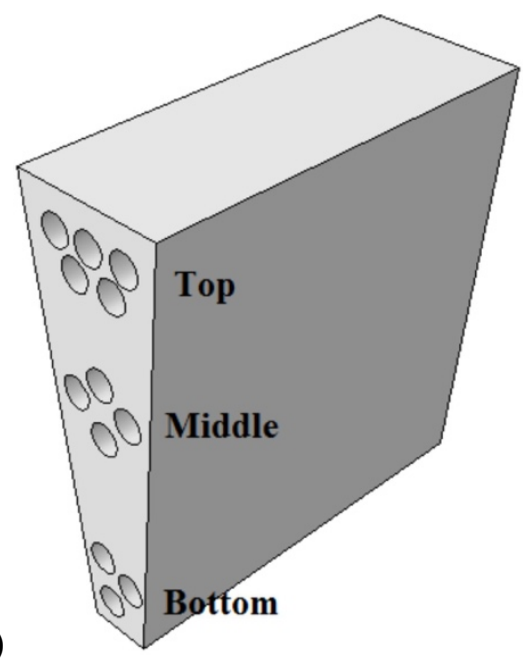

(b)

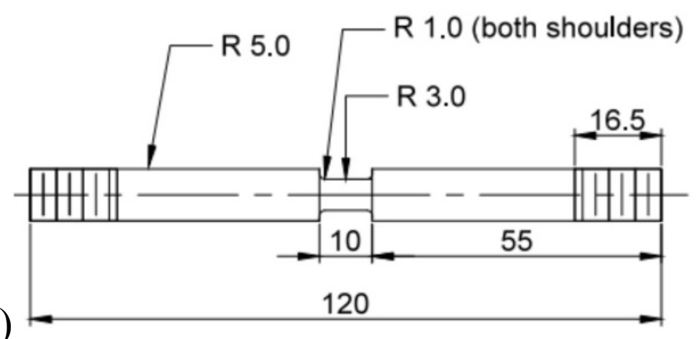

Fig. 3 (a) Schematic of the wedge casting and the tensile test sample locations showing the relative positions of the bottom, middle, and top test specimens; (b) Tensile specimen geometry (dim. are in $\mathrm{mm}$ ) 


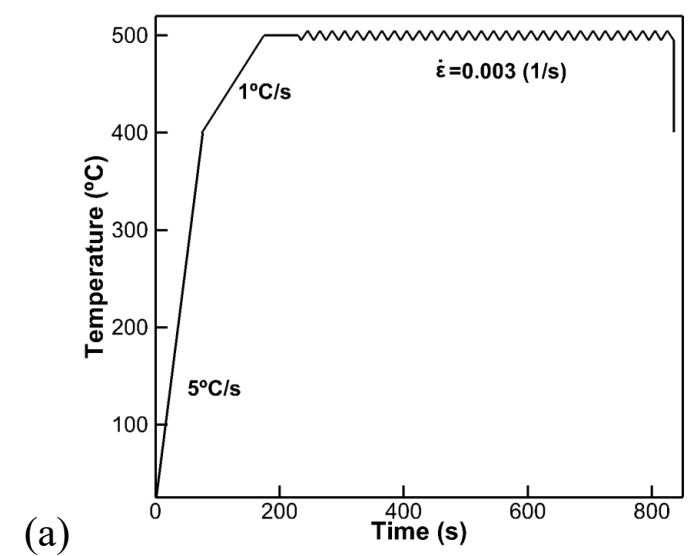

Fig. 4. (a) Gleeble testing procedure, consisting of four steps: rapid heating, slow heating to the test temperatures, holding, and isothermal tensile deformation. On the graph, the deformation stage is represented by the oscillations.

The metallographic images were acquired using a "Nikon1 EPIPHOT 300" optical microscope equipped with a digital camera. The images were then analyzed using the ImageJ software to measure the SDAS and grain size. Finally, SEM images were taken of the fracture surfaces of B206 and A356 samples after being deformed to failure in order to examine the extent to which liquid was present in the microstructure at the time of failure.

\section{Results and Discussion}

In this section, the results obtained from optical microscopy, thermomechanical testing and fractography, are presented.

\subsection{Optical microscopy results}

Figures 5 and 6 show micrographs of samples taken from the (I) bottom, (II) middle, and (III) top of the as-cast B206 and A356 wedges, respectively. The cooling rates indicated in the figure legends were evaluated from thermocouple measurements made during one of the castings. Focussing first on B206, the microstructure contains primarily globular/dendritic $\alpha$-Al grains (in brown/grey), along with a eutectic mixture of $\mathrm{Al}$ and $\mathrm{Cu}$ at the grain boundaries (in white). It has been previously reported for this alloy that the eutectic region consists additionally of Fe/Mn phases and $\mathrm{Al}_{2} \mathrm{Cu}(20)$. The grain boundaries may be discerned by the continuous boundary of the white eutectic surrounding them. As can be seen there is a gradual increase in the grain size and SDAS with increasing distance from the chill/decreasing cooling rate (images I through III). The grain size for B206 was $\sim 128 \mu \mathrm{m}$ at $5 \mathrm{~mm}$ from the chill and increased up to $325 \mu \mathrm{m}$ at $135 \mathrm{~mm}$ from the chill - due a significant reduction in cooling rate. 
In the case of the A356, the primary $\alpha$-Al phase appears as the light grey phase and the eutectic appears as the mixture of light and dark phases. The microstructure may be characterized as equiaxed-dendritic. The grain boundaries are more difficult to discern in the A356 samples; however, as can be seen there is a gradual increase in the SDAS with increasing distance from the chill/decreasing cooling rate (images I through III) (21). As can be seen, there was a significant increase in SDAS occurring with increasing distance from the chill. The values ranged from $\sim 43$

$\mu \mathrm{m}$ spacing at $5 \mathrm{~mm}$ up to $\sim 124 \mu \mathrm{m}$ spacing at $130 \mathrm{~mm}$. The variation in grain size for B206 and SDAS for A356 will be used for the yield strength and ductility analysis in Figures 9 and 10.

\subsection{Thermo-mechanical test results}

Figures 7 and 8 show a series of engineering stress-strain curves obtained from the as-cast B206 and A356 samples, respectively, taken from the bottom of the wedge (location I). Figure 7 (a) shows the results for B206 at 500,520,540,550 and $570^{\circ} \mathrm{C}$. Figure 7 (b) shows the results for 550 and $570^{\circ} \mathrm{C}$, with the $x$ and $y$-axes scaled to better reveal the behaviour at elevated temperature. Figure 8 (a) shows the results for A356 at 500, 520, 540, 550, 560 and $570^{\circ} \mathrm{C}$. Figure 8 (b) shows the results for 560 and $570^{\circ} \mathrm{C}$, with the $x$ and $y$-axes also scaled to better reveal the behaviour at elevated temperature. All the temperatures tested are close to, or within, the semi-solid regime. Referring back to Figure 1, the maximum temperature tested, $570^{\circ} \mathrm{C}$, corresponds to a solid fraction of approximately 0.9 for B206 and 0.8 for A356. 


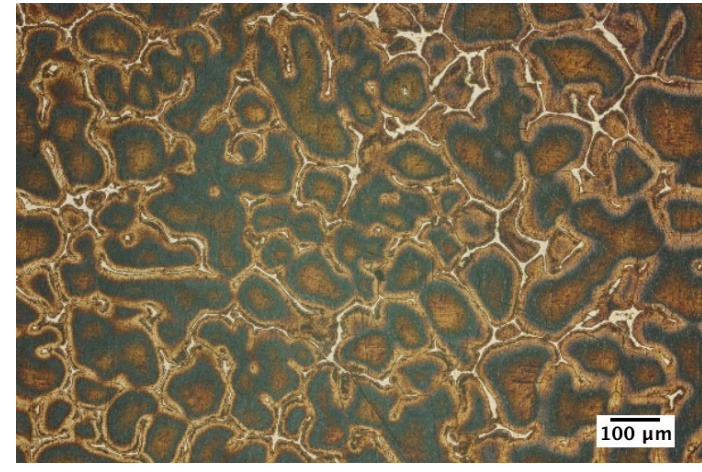

I

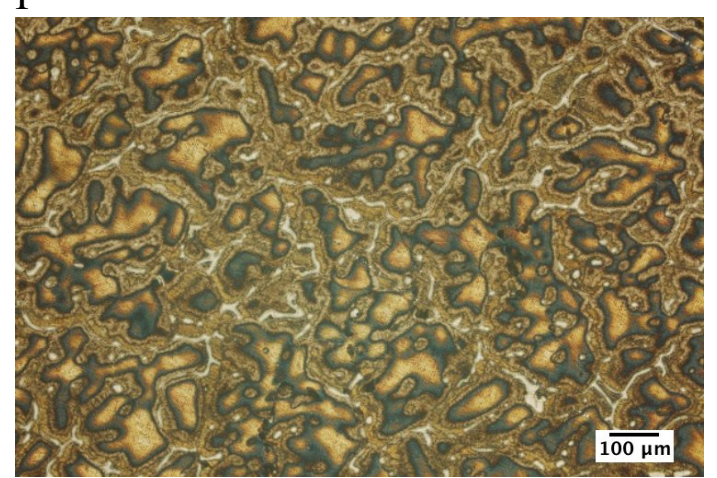

II

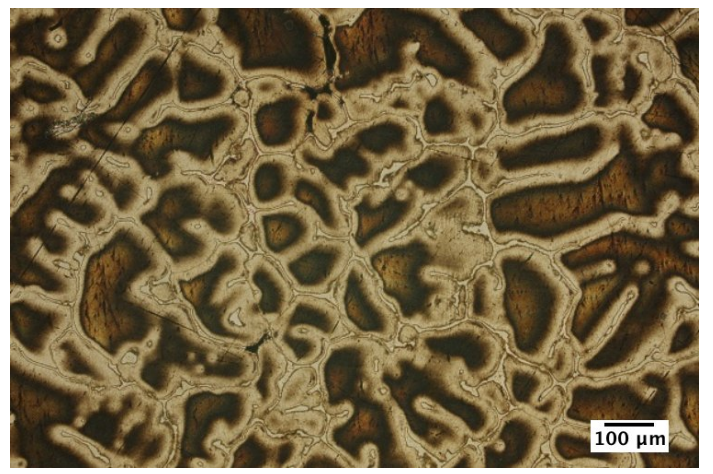

III

Fig. 5. Optical micrographs of B206 taken from the (I) bottom $\left(\mathrm{CR}=2.5^{\circ} \mathrm{C} / \mathrm{s}\right)$, (II) middle $\left(\mathrm{CR}=0.14{ }^{\circ} \mathrm{C} / \mathrm{s}\right)$, and (III) top $\left(\mathrm{CR}=0.04^{\circ} \mathrm{C} / \mathrm{s}\right)$ of the wedge casting.

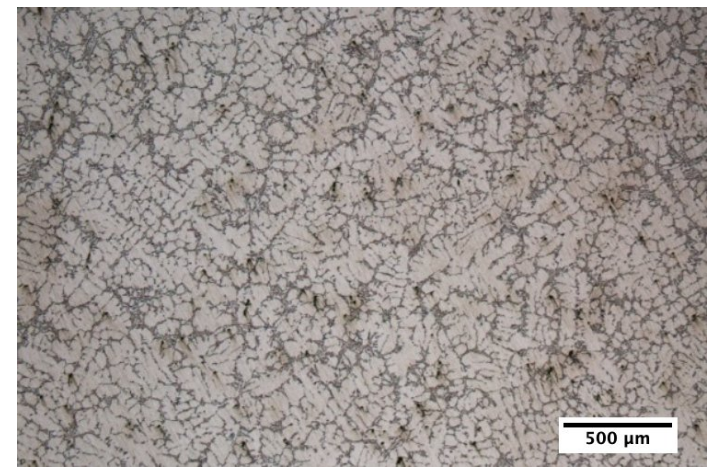

I

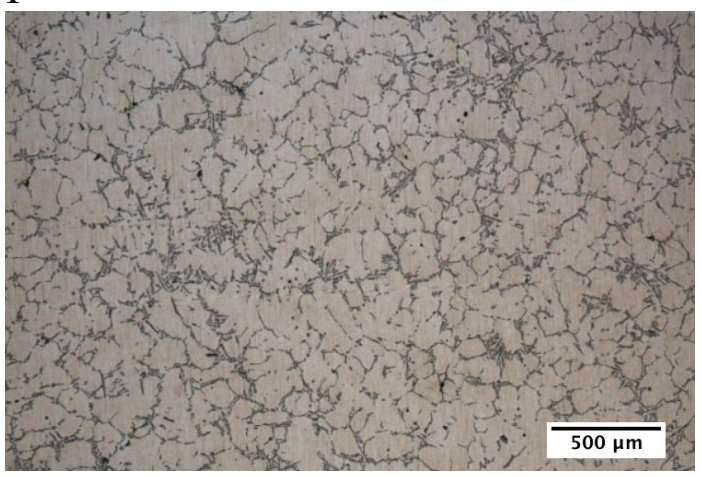

II

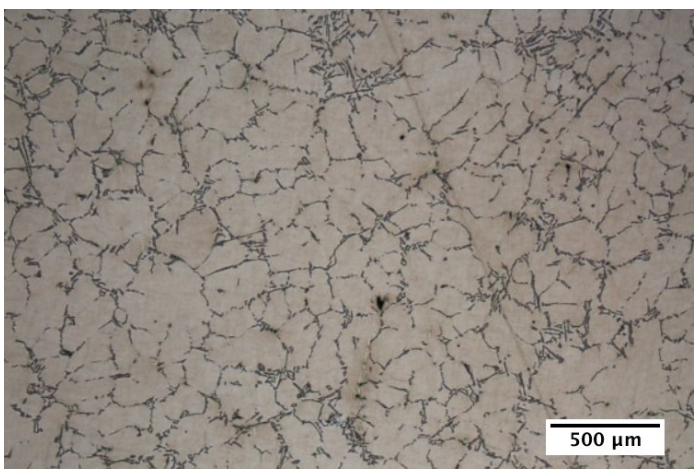

III

Fig. 6. Optical micrographs of A356 taken from the (I) bottom $\left(\mathrm{CR}=1.81^{\circ} \mathrm{C} / \mathrm{s}\right)$, (II) middle $\left(\mathrm{CR}=0.12^{\circ} \mathrm{C} / \mathrm{s}\right)$, and (III) top $\left(\mathrm{CR}=0.08^{\circ} \mathrm{C} / \mathrm{s}\right)$ of the wedge castings. 


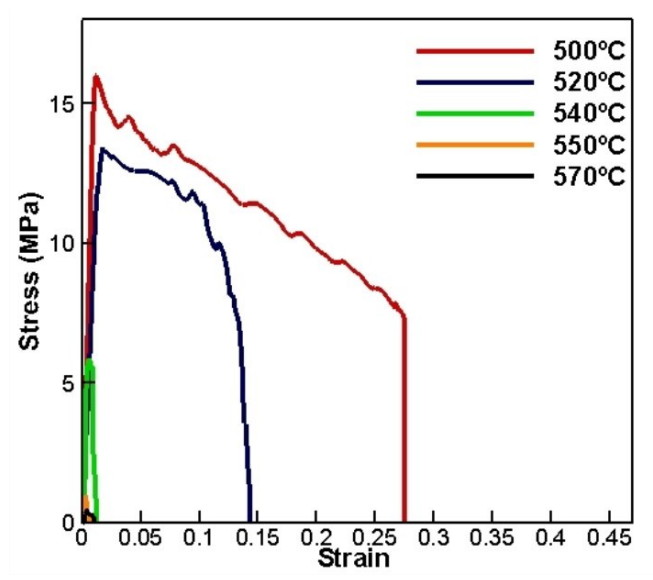

(a)

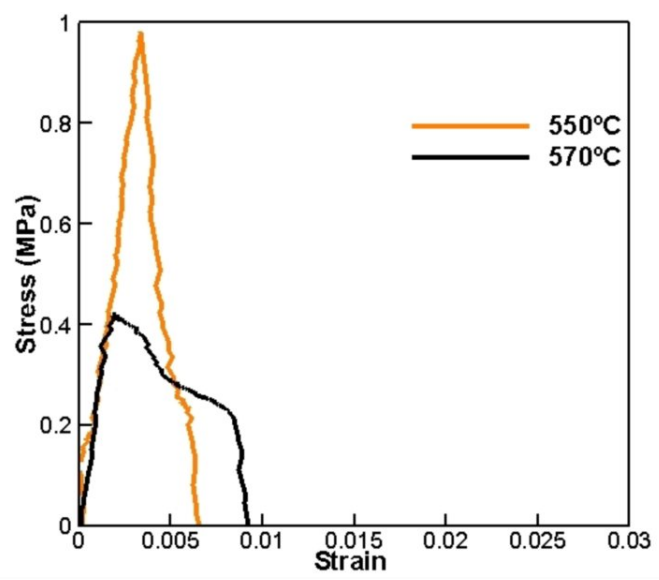

(b)

Fig. 7. Selected engineering stress-strain curves of as-cast B206 alloy taken from the bottom of the wedge (location I) tested at the temperatures indicated in the legend. (See online version for colour-coding of legend)

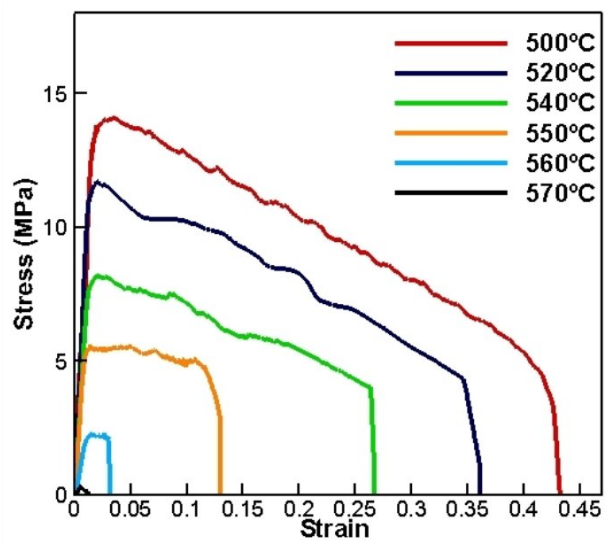

(a)

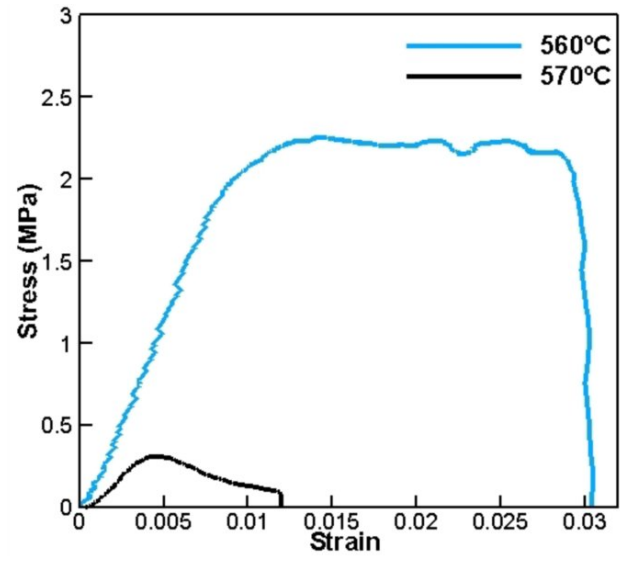

(b)

Fig. 8. Selected engineering stress-strain curves of as-cast A356 alloy taken from the bottom of the wedge (location I) tested at the temperatures indicated in the legend. (See online version for colour-coding of legend)

For both alloys, it can be seen that the stress linearly increases to a maximum value with increasing strain in what would appear to be the elastic deformation regime. The stress then decreases gradually for varying lengths of strain (dependent on temperature) before rapidly dropping associated with sample failure. Applying a conventional approach to interpretation of this data, i.e. based on room temperature behaviour, the semi-solid yield, GYs and semi-solid ultimate tensile stress, $\sigma_{U T S}$, appear to be close to equivalent in both materials. In the case of B206 they are virtually identical, whereas for A356 there appears to be some deviation at higher 
temperatures before reaching the peak load. In the 550 and $560^{\circ} \mathrm{C}$ A356 samples, elastic-perfectly plastic behaviour is exhibited for an appreciable range of strain prior to failure. Generally, it is seen that the semi-solid yield stress and ductility show a high degree of sensitivity to temperature, decreasing significantly with small increases in temperature. The lack of a post-yield region of permanent deformation in all but two of the cases suggests rapid strain localization, likely within the pockets of liquid present in the microstructure.

\subsubsection{Yield Stress}

Although the test results indicate that there is little merit in using $\sigma_{\mathrm{YS}}$ as an indicator of hot tearing, or sample failure, $\sigma_{\mathrm{YS}}$ is nonetheless critical in modelling the on-set of permanent deformation and predicting the accumulation of post-yield strain (damage) in semi-solid materials. The measured engineering $\sigma_{Y S}$ for the B206 and A356 materials, as a function of solid fraction and grain size, are shown in Figure 9 (a) and (b), respectively. For B206, the data encompasses a range of solid fraction from 1 to 0.9 and range of grain size from 200-325 $\mu \mathrm{m}$. For A356, the data encompasses a range of solid fractions from 1 to 0.8 and a range of secondary dendrite arm spacing from $43-124 \mu \mathrm{m}$. For most of the test data, the classical $0.2 \%$ offset method was used to define the yield stress. For samples with very low ductility, i.e. with a failure strain smaller than $0.2 \%$, the highest stress was reported as the yield stress.

Figure 9 (a) shows that for all B206 samples, decreasing the solid fraction from 1 to 0.9 sharply decreases the yield stress. Quantitatively, the data shows a reduction from $\sim 16 \mathrm{MPa}$ to less than 1 $\mathrm{MPa}$ for a grain size of $128 \mu \mathrm{m}$; from $\sim 14 \mathrm{MPa}$ to less than $1 \mathrm{MPa}$ for a grain size of $220 \mu \mathrm{m}$; and from $\sim 12 \mathrm{MPa}$ to less than $1 \mathrm{MPa}$ for a grain size of $325 \mu \mathrm{m}$. Hence, there is a strong influence of grain size, particularly at the higher solid fractions examined. Figure 9 (b) shows that a similar trend is found in the A356 results as compared to the B206 results, but with some differences. Most notably, the drop in $\sigma_{\mathrm{YS}}$ is lower in magnitude and occurs over a broader range of solid fractions (1 to 0.8 ). Additionally, while there is also an influence of microstructural feature size, the effect is smaller than that observed in B206. Quantitatively, for A356 the data shows a reduction from $\sim 11 \mathrm{MPa}$ to less than $1 \mathrm{MPa}$ for an SDAS of $43 \mu \mathrm{m}$; from $\sim 9 \mathrm{MPa}$ to less than 1 MPa for an SDAS of $90 \mu \mathrm{m}$; and from $\sim 8 \mathrm{MPa}$ to less than $1 \mathrm{MPa}$ for an SDAS of $124 \mu \mathrm{m}$.

There are a number of factors that contribute to the significant reduction in $\sigma_{\mathrm{YS}}$ with increasing liquid fraction (decreasing solid fraction) in both B206 and A356. First, as the liquid fraction increases there will be an associated reduction in the load bearing material (i.e. the interconnected 
solid). Second, as noted by (Li et al., 2012) the grains will change morphology becoming more regular and spherical enabling rotation and some rearrangement during deformation. Third, as the grains become fully surrounded by liquid they are able to slide, allowing increased motion (Chen et al., 2015). In the case of B206, (Eskin and Katgerman, 2007) identified that the grains are more globular in morphology, which allows them to rearrange easily by sliding, resulting in a more rapid reduction in $\sigma_{\mathrm{YS}}$ with increasing liquid fraction. For A356, the dendritic grains are more irregular and entangled with each other, and thus the semi-solid structure cannot as readily accommodate strain by rearrangement of the grains (Eskin et al., 2004). Hence, in this alloy there is both a more gradual reduction in $\sigma_{Y S}$ with temperature and the retention of a measurable $\sigma_{Y S}$ to solid fractions down to 0.8. The results also show that larger microstructure features (grain size / SDAS) deteriorate the semi-solid yield strength. Larger microstructure features will lead to wider liquid channels for a given fraction solid; this localizes strain within the channels thus reducing stress prior to fracture. The greater sensitivity to microstructure feature size displayed by B206 may also be related to the more globular structure of B206 as the smaller grains are able to more easily rotate and slide relative to one another. In A356, there is a secondary effect, namely, the large eutectic fraction which enables significant liquid feeding to counteract the deformation of the liquid channels. This decreases the sensitivity of semi-solid yield strength to SDAS.

\subsubsection{Ductility}

As previously discussed, the measurement of $\sigma_{\mathrm{Ys}}$ in semi-solid alloys is an important property in identifying the onset plastic, or permanent deformation. As noted by a number of researchers, (D'Elia et al., 2014; Eskin et al., 2004; Mathier et al., 2008) it is not believed, however, to be the key property of interest for predicting hot tearing susceptibility. (A.B. Phillion et al., 2008) has shown that there is considerable variability in the ductility, or strain to failure, in these materials as a result of the post yield behaviour being dominated by the rapid accumulation and localization of damage. Hence the need to quantify strain-to-failure.

The engineering fracture strain for the B206 and A356 are shown in Figure 10 (a) and (b), respectively, for the samples extracted from the bottom, middle, and top of the wedge-shaped castings. It should be noted that the ductility was measured based on the movement of the crosshead up to the point of fracture, as it was not possible to use a clip-type strain gauge. For B206, Figure 10 (a), the results show a rapid decrease in ductility between solid fractions 1 and 0.98 , whereas, between 0.98 and 0.9 , the reduction is more gradual. Quantitatively, the data shows a 
reduction from a fracture strain of $\sim 0.28$ to less than 0.01 for a grain size of $128 \mu \mathrm{m}$; from $\sim 0.175$ to less than 0.01 for a grain size of $220 \mu \mathrm{m}$; and from $\sim 0.06$ to less than 0.01 for a grain size of $325 \mu \mathrm{m}$. Hence, there is a strong influence of grain size on ductility in semi-solid B206. For A356, Figure 10 (b), the results show a similar trend to B206, but with some significant differences. Most notably, the drop in the strain to failure is more gradual, particularly at higher solid fractions ( 1 to 0.9), and occurs over a broader range of solid fraction (down to 0.8). In terms of the magnitude, for A356 the data shows a reduction in fracture strain from $\sim 0.35$ to less than 0.01 for an SDAS of $43 \mu \mathrm{m}$; from $\sim 0.325$ to less than 0.01 for an SDAS of $90 \mu \mathrm{m}$; and from $\sim 0.275$ to less than 0.01 for an SDAS of $124 \mu \mathrm{m}$.

The effect of microstructure size on the semi-solid ductility is seen to be complex. At lower fraction solids, the grains are less entangled and thus changes in SDAS or grain size appear to have a negligible effect on ductility. At high fraction solid, as microstructure size is a function of cooling rate, the resulting difference in micro-segregation may depress the solidus temperature, and the distribution of eutectic particles, thereby changing the apparent tensile properties Both alloys show some variation in ductility, although the influence of microstructural feature size on A356 is smaller than that observed in B206. The reason for the difference in ductility between the two alloys is consistent with the argument presented previously, with respect to the differences observed in yield stress, with one additional comment. It would appear that the more dendritic structure associated with A356 is able to better distribute strain thus delaying the onset of coalescence and localization of damage.

(a)

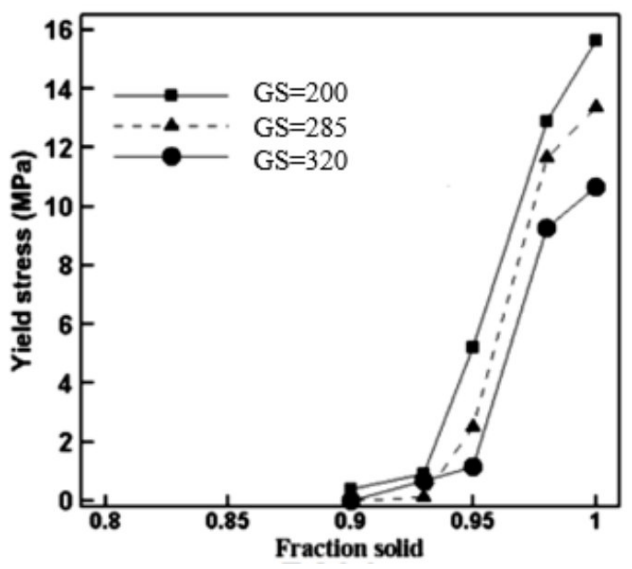

(b)

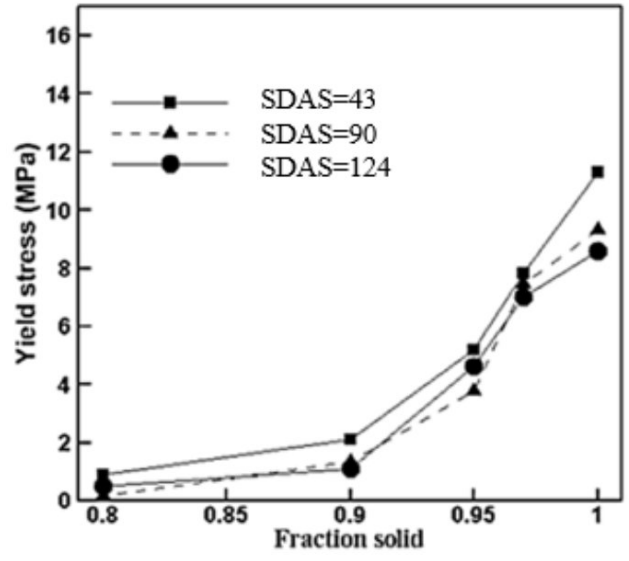

Fig. 9. Variation in Yield Stress with solid fraction for (a) B206 and (b) A356 alloys. The term GS in (a) represents the average grain size in $\mu \mathrm{m}$, while the term SDAS in (b) represents the secondary dendrite arm spacing in $\mu \mathrm{m}$. 


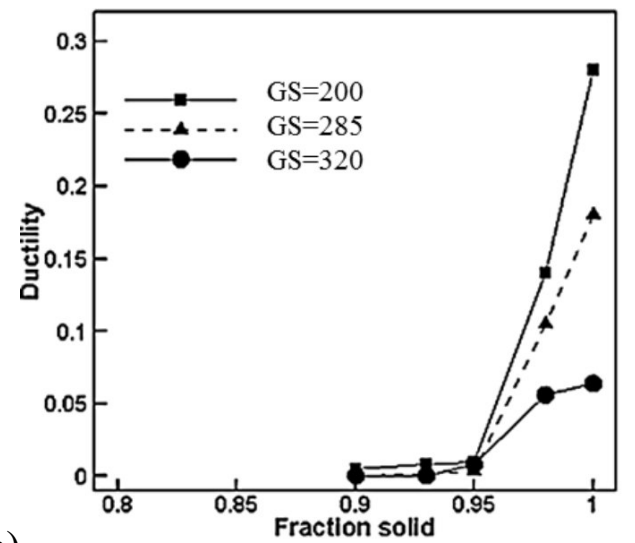

(a)

(b)

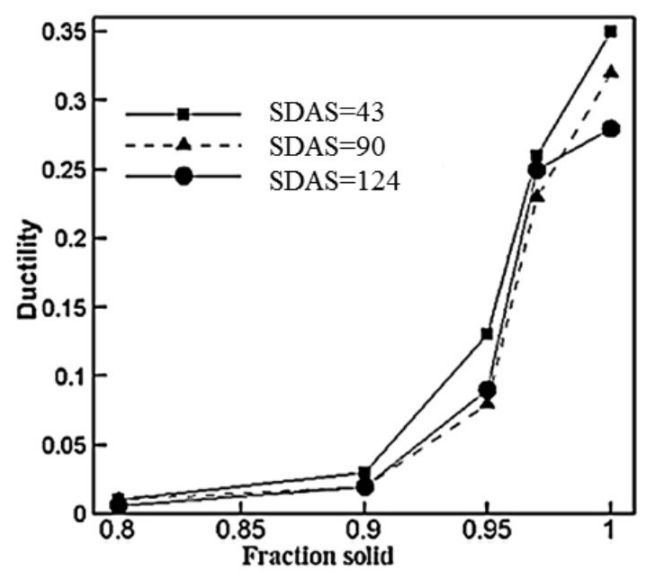

Fig. 10. Variation in ductility with solid fraction for (a) B206 and (b) A356 alloys.

\subsection{Fractography}

The fracture surfaces of B206 and A356 after mechanical testing were examined in order to investigate the effect of temperature on the fracture surface morphology. Figure 11 shows SEM images of a B206 sample taken from the bottom of the wedge and tested at $540^{\circ} \mathrm{C}$ and $570^{\circ} \mathrm{C}$. Figure 12 shows SEM images of an A356 sample also taken from the bottom of the wedge but tested at $500^{\circ} \mathrm{C}$ and $540^{\circ} \mathrm{C}$. The images in Figure 11 (a) and Figure 12 (a) were taken from samples tested close to the solidus based on the curves given in Figure 1, whereas the images in Figure 11 (b) and Figure 12 (b) are approximately consistent with solid fractions of 0.9 in B206 and 0.8 in A356. It should be noted that images of fracture surfaces from samples tested in the Gleeble can be difficult to interpret as there can be rapid heating and arcing of the fracture surface in the last stage of failure prior to the flow of current being terminated. Comparing the two B206 fracture surfaces, both clearly show intergranular failure. The grains appear fairly spheroidal and smooth. The smooth, glass-like, morphology could be evidence of the presence of liquid films on the grain boundaries at failure. In Figure 11 (a), as denoted by arrows, there is evidence of small porosity at the junction of grains. In Figure 11 (b), there is evidence of increased spheroidization of the grains at $570{ }^{\circ} \mathrm{C}$ and, as denoted by arrows, and there is also evidence of a change in surface morphology in some of the grains from glass-like to rough. This may indicate areas that were dry and free from liquid at the time of failure and could potentially represent areas of large, interconnected pores. The fracture surfaces of the A356 samples are very different than in B206. The facture surface in Figure 12 (a) at $540{ }^{\circ} \mathrm{C}$ is highly irregular and is typical of ductile failure, with little evidence of liquid at the time of failure. At $570{ }^{\circ} \mathrm{C}$, Figure 12 (b), the fracture surface is less irregular and shows areas with a smooth surface that could indicate liquid present at the time of failure. 


\subsection{Comparison to other work}

Figure 13 compares the measured semi-solid yield stresses of A356 with a SDAS of $43 \mu \mathrm{m}$ against the work of (Nguyen T G et al., 1994) $\left(\dot{\varepsilon}=0.008 \mathrm{~s}^{-1}\right)$ and (Benke et al., 2009) $\left(\dot{\varepsilon}=0.005 \mathrm{~s}^{-1}\right)$. As can be seen, the newly-collected data is quite similar to the prior results. Specifically, the yield stress at solid fractions higher than 0.80 are in good agreement with those measured by Nguyen, while the measured yield stress at $f_{\mathrm{s}}=0.80$ closely matches the Benke data. The rigidity point of 0.8 is also seen to be similar to Benke's value. The results in this study validate and extend these prior experiments by additionally examining the role of microstructure.

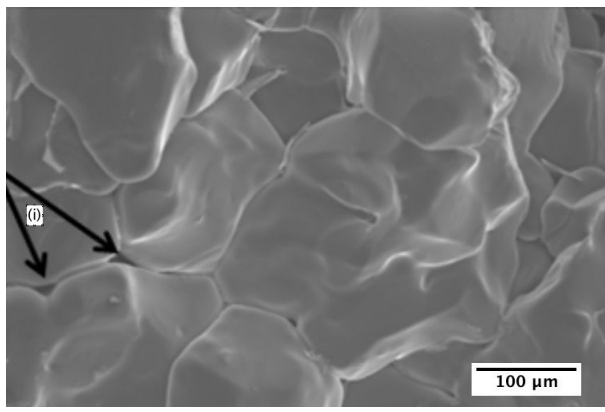

(a)

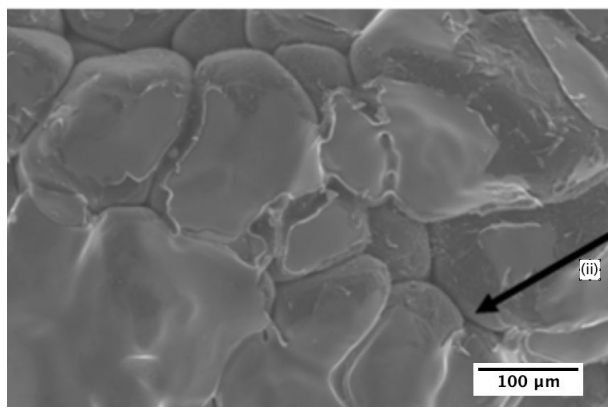

(b)

Fig. 11. SEM images of the fracture surface of as-cast B206 specimens (a) $540^{\circ} \mathrm{C}$ and (b) $570^{\circ} \mathrm{C}$. Marker (i) identifies the porosity at grain triple junctions while (ii) identifies an example of a dry grain boundary.

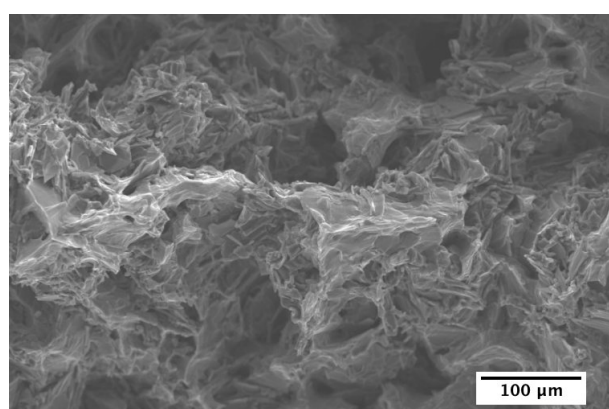

(a)

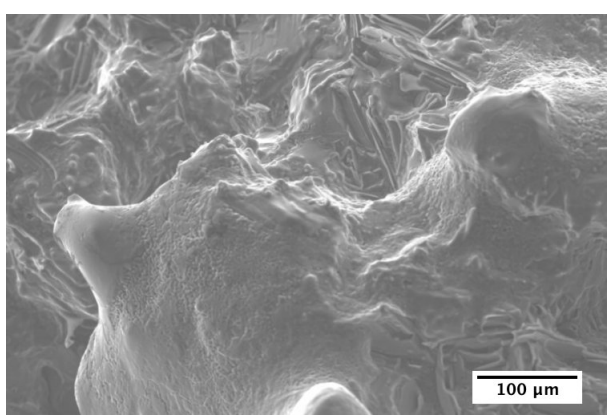

(b)

Fig. 12. SEM images of the fracture surface of as-cast $\mathrm{A} 356$ specimens (a) $500^{\circ} \mathrm{C}$ and (b) $540^{\circ} \mathrm{C}$. 


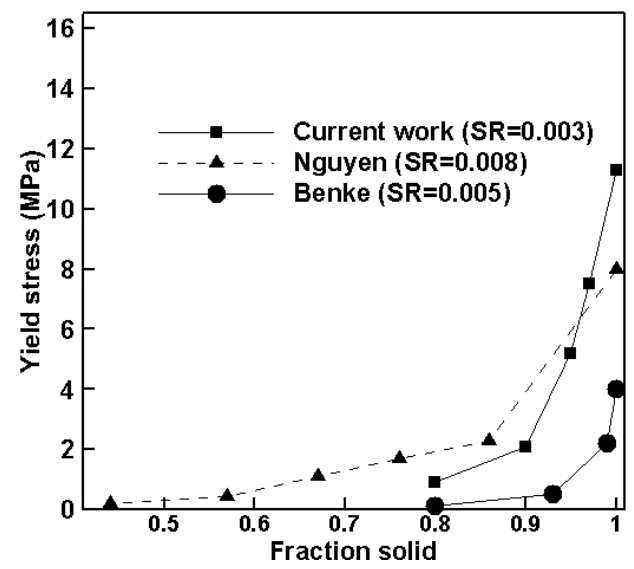

Fig. 13. Comparison of the A356 semi-solid yield stress measurements in this work to prior results by (Nguyen T G et al., 1994) and (Benke et al., 2009).

\section{Summary and Conclusions}

The semi-solid tensile properties of B206 and A356 were characterized as a function of solid fraction over a range of $0.8<f_{\mathrm{s}}<1$. Additionally, by extracting the samples from a wedgeshaped casting at different distances from the chill (narrow end of the wedge) a range of microstructures were examined. The results provide quantitative values of the yield stress and ductility of these important aluminum casting alloys that can be used for modelling applications. It was shown that at relatively high solid fractions $\left(0.95<f_{\mathrm{s}}<1\right)$, B206 shows higher yield strength as compared to A356. However, at lower solid fractions $\left(0.8<f_{\mathrm{s}}<0.95\right)$, the properties are reversed. In terms of the effects of microstructure, it was seen that a decrease in both SDAS and grain size improves tensile properties especially at high solid fractions where hot tearing is most prevalent. B206 showed a larger sensitivity to microstructure length scale (grain size) than did A356 (SDAS). In practice, some reduction in hot tearing could be achieved by using a grain refiner or by increasing the solidification rate. The addition of a grain refiner would be the preferred option as it would avoid the potential for higher thermal stresses associated with higher cooling rates.

\section{Acknowledgements}

The authors are grateful for the funding provided by the Natural Engineering and Sciences Research Council under the Automotive Partnership Canada Program, and Canadian Autoparts Toyota Inc, and for the funding provided by the Natural Sciences and Engineering Research Council of Canada and partner companies under the Strategic Project "Through-Process Modelling: Castings for Marine Energy Systems'’.

\section{References}

Benke, S., Dziallach, S., Laschet, G., Prahl, U., Bleck, W., 2009. Modeling of the uniaxial tensile 
and compression behavior of semi-solid A356 alloys. Comput. Mater. Sci. 45, 633-637. https://doi.org/10.1016/j.commatsci.2008.08.011

Bolouri, A., Liu, K., Chen, X.-G., 2016. Effects of Iron-Rich Intermetallics and Grain Structure on Semisolid Tensile Properties of Al-Cu 206 Cast Alloys near Solidus Temperature. Metall. Mater. Trans. A-PHYSICAL Metall. Mater. Sci. 47A, 6466-6480. https://doi.org/10.1007/s11661-016-3744-8

Chen, Y.-N., Luo, C., Huo, Y.-Z., Bai, F., Zhao, Y.-Q., Ma, X.-D., 2015. Effect of Cu concentration on the semi-solid deformation behavior and microstructure of Ti-Cu alloy. Adv. Mech. Eng. 7. https://doi.org/10.1177/1687814015587428

Colley, L.J., Wells, M.A., Maijer, D.M., 2004. Tensile properties of as-cast aluminum alloy AA5182 close to the solidus temperature. Mater. Sci. Eng. A 386, 140-148. https://doi.org/10.1016/j.msea.2004.07.019

D’Elia, F., Ravindran, C., Sediako, D., Kainer, K.U., Hort, N., 2014. Hot tearing mechanisms of B206 aluminum-copper alloy. Mater. Des. 64, 44-55. https://doi.org/10.1016/j.matdes.2014.07.024

Eskin, D.G., 2008. Physical Metallurgy of Direct Chill Casting of Aluminum Alloys. CRC Press, Boca Raton.

Eskin, D.G., Katgerman, L., 2007. A quest for a new hot tearing criterion. Metall. Mater. Trans. A Phys. Metall. Mater. Sci. 38 A, 1511-1519. https://doi.org/10.1007/s11661-007-9169-7

Eskin, D.G., Suyitno, Katgerman, L., 2004. Mechanical properties in the semi-solid state and hot tearing of aluminium alloys. Prog. Mater. Sci. 49, 629-711. https://doi.org/10.1016/S00796425(03)00037-9

Fabrègue, D., Deschamps, a., Suéry, M., Poole, W.J., 2006a. Rheological behavior of Al-Mg-Si$\mathrm{Cu}$ alloys in the mushy state obtained by partial remelting and partial solidification at high cooling rate. Metall. Mater. Trans. A 37, 1459-1467. https://doi.org/10.1007/s11661-0060090-2

Fabrègue, D., Deschamps, A., Suery, M., Drezet, J.M., 2006b. Non-isothermal tensile tests during solidification of Al-Mg-Si-Cu alloys: Mechanical properties in relation to the phenomenon of hot tearing. Acta Mater. 54, 5209-5220. https://doi.org/10.1016/j.actamat.2006.06.027

Haghdadi, N., Phillion, A.B., Maijer, D.M., 2015. Microstructure Characterization and Thermal Analysis of Aluminum Alloy B206 During Solidification. Metall. Mater. Trans. A 46, 2073-2081. https://doi.org/10.1007/s11661-015-2780-0

Hamadellah, A., Bouayad, A., Gerometta, C., 2017. Hot tear characterization of AlCu5MgTi and AlSi9 casting alloys using an instrumented constrained six rods casting method. J. Mater. Process. Technol. 244, 282-288. https://doi.org/10.1016/j.jmatprotec.2017.01.030

Heydari, D., Fard, A.S., Bakhshi, A., Drezet, J.M., 2014. Hot tearing in polycrystalline Ni-based IN738LC superalloy: Influence of Zr content. J. Mater. Process. Technol. 214, 681-687. https://doi.org/10.1016/j.jmatprotec.2013.10.001

Lemieux, A., Langlais, J., Chen, X.G., 2012. Reduction of Hot Tearing of Cast Semi-Solid 206 Alloys. Solid State Phenom., Solid State Phenomena 192-193, 101-106. https://doi.org/10.4028/www.scientific.net/SSP.192-193.101

Li, S., Apelian, D., Sadayappan, K., 2012. Hot Tearing in Cast Al Alloys: Mechanisms and Process Controls. Int. J. Met. 6, 51-57. https://doi.org/10.1007/BF03355533

Major, J.F., Sigworth, G.K., 2006. Chemistry/Property Relationships in AA206 Alloys. AFS Trans. 114, 117-128. 
Mathier, V., Grasso, P.D., Rappaz, M., 2008. A new tensile test for aluminum alloys in the mushy state: Experimental method and numerical modeling. Metall. Mater. Trans. A Phys. Metall. Mater. Sci. 39 A, 1399-1409. https://doi.org/10.1007/s11661-008-9529-y

Mohseni, S.M., Phillion, A.B., Maijer, D.M., 2016. Modelling the constitutive behaviour of aluminium alloy B206 in the as-cast and artificially aged states. Mater. Sci. Eng. A 649. https://doi.org/10.1016/j.msea.2015.09.118

Nguyen T G, Favier, D., Suery, M., 1994. Theoretical and Experimental-Study of the Isothermal Mechanical-Behavior of Alloys in the Semisolid State. Int. J. Plast. 10, 663-693. https://doi.org/10.1016/0749-6419(94)90028-0

Phillion, A.B., Cockcroft, S.L., Lee, P.D., 2008. A new methodology for measurement of semisolid constitutive behavior and its application to examination of as-cast porosity and hot tearing in aluminum alloys. Mater. Sci. Eng. A 491, 237-247. https://doi.org/10.1016/j.msea.2008.01.078

Phillion, A.B., Lee, P.D., Maire, E., Cockcroft, S.L., 2008. Quantitative assessment of deformation-induced damage in a Semisolid aluminum alloy via X-ray microtomography. Metall. Mater. Trans. A Phys. Metall. Mater. Sci. 39. https://doi.org/10.1007/s11661-0089584-4

Sigworth, G.K., 1996. Hot Tearing of Metals. AFS Trans. 104, 1053-1062.

Thompson, S., Cockcroft, S.L., Wells, M.A., 2004. Advanced light metals casting development: solidification of aluminium alloy A356. Mater. Sci. Technol. 20, 194-200. https://doi.org/10.1179/026708304225011199

Van Haaften, W.M., Kool, W.H., Katgerman, L., 2002a. Tensile behaviour of semi-solid industrial aluminium alloys AA3104 and AA5182. Mater. Sci. Eng. A 336, 1-6. https://doi.org/10.1016/S0921-5093(01)01987-6

Van Haaften, W.M., Magnin, B., Kool, W.H., Katgerman, L., 2002b. Constitutive behavior of as-cast AA1050, AA3104, and AA5182. Metall. Mater. Trans. A Phys. Metall. Mater. Sci. 33, 1971-1980. https://doi.org/10.1007/s11661-002-0030-8 